\title{
CRITICAL SUCCESS FACTOR MODEL FOR ENTERPRISE ARCHITECTURE IMPLEMENTATION
}

\author{
Babak Darvish Rouhani ${ }^{1^{*}}$, Rodina Binti Ahmad ${ }^{2}$ Fatemeh Nikpay $^{3}$, Reza Mohamaddoust \\ ${ }^{1,4}$ Department of Computer Engineering and Information Technology, Payame Noor University ,Tehran, Iran \\ ${ }^{2,3}$ Faculty of Computer Science and Information Technology, University of Malaya, 50603 Kuala Lumpur, Malaysia \\ Email:darvishrouhani@pnu.ac.ir; rodina@um.edu.my; fa.nikpay@siswa.um.edu.my; pnu1392@yahoo.com
}

ABSTRACT

DOI: https://doi.org/10.22452/mjcs.vol32no2.4

Enterprise Architecture (EA) is a strategy to attain alignment between an enterprise's business and Information Technology (IT) to increase the competitiveness of an enterprise. In EA implementation, Critical Success Factors $(C S F s)$ refer to factors that may facilitate the successful implementation of the EA. This research presents a CSF model based on an exhaustive literature review and empirical data from practitioners to identify rationalised CSFs. EA implementation projects that do not fully utilize the CSFs may result in inappropriate directions and dissatisfied EA project stakeholders. A quantitative research methodology is applied in this study using questionnaires to evaluate the proposed model. The respondents include enterprise architects, IT managers, and IT consultants with considerable knowledge of EA concepts. Statistical analysis is used to identify the relationships between the proposed CSFs and the success of EA implementation. From the results, the proposed CSF model is significantly related to EA implementation success. The highest-ranking CSF is governance, indicating the importance of governance in the success of EA implementation. Moreover, the proposed CSF model appears to facilitate achieving the desired architecture. By understanding the CSF model at the onset of a project, practitioners can better plan and focus on the CSFs to achieve the desired results.

Keywords: Enterprise Architecture; Enterprise Architecture Implementation; Critical Success Factors; CSF Model

\subsection{INTRODUCTION}

Enterprise Architecture (EA) provides a comprehensive strategy and environment for aligning an enterprise's business with Information Technology (IT) [1][2]. Motivational factors for EA include increasing competitiveness and coping with future changes. In order to offer an appropriate environment for the alignment between business and IT, EA describes the current architecture (As-Is), elaborates the desired architecture (To-Be), and represents a migration plan for the transition from the current to the desired architecture for an enterprise [3][4]. Four architectural levels-business, data, application, and infrastructure-need to be described in the three aforementioned EA project stages [5][6].

Robust EA implementation facilitates a stable and flexible environment, leading to innovation, transformation and consequently, enterprise stability and flexibility [2][7][8][9][10][11][12]. Besides, implementing EA enables enterprises to reach the desired goals and gain certain advantages such as impressive IT operations; reduced ITbusiness alignment risks; greater flexibility for the enterprise's business strategy; accelerated product innovation; bridging gaps between business and IT; greater focus on the enterprise requirements; and enabling appropriate enterprise response to challenges driven by business and environmental changes [7][10][13][51].

Critical Success Factors (CSFs) are elements that should be implemented well through IT projects to ensure the success of both managers and enterprises [14][15]. Focusing on CSFs when implementing EA, it expedites the performance and provides holistic competitiveness for enterprises. CSFs normally highlight fundamental issues regarding current and future processes [16][17][50]. In this study, a CSF model for EA implementation is proposed and the identified factors are ranked in terms of their importance to EA implementation. The target audience of this research is twofold. First, the study is aimed at researchers who are studying and exploring ways to increase the success of EA implementation. The second target audience comprises practitioners who would like to know which factors affect the successful implementation of EA for application in their EA projects. The remainder of this study is organized as follows. Section 2 presents related works. Section 3 describes the proposed CSF model factors and Section 4 includes the data analysis results. Sections 5 and 6 present a discussion and conclusions, respectively. 
Most enterprises utilize EA to overcome complexities in their business processes and Information System (IS) integration [18][19]. In this regard, appropriate EA implementation assists enterprises to address organizational concerns. There are a few studies on CSFs for EA implementation [20][14] and this section describes current research works in this area.

Kamogawa (2008) investigated the effective CSFs in EA and found that CSFs can create an appropriate business vision and IT alignment for an enterprise. An enterprise may encounter changes in their business environment, such as new products and services. As such, to ensure enterprise sustainability through business processes, aligning the enterprise's IT and business vision is one of the key elements to survival in the business environment and IT project success. Enterprises should focus on CSFs within EA implementation projects [21]. In Kamogawa's model, the IT governance factor has a significant role in IT implementation as it specifies a decision-making and responsibility structure to encourage the intended behaviour in IT to be used for internal control and risk management. EA cognition with the management capability may influence the effectiveness of IT governance [21]. This model focuses on IT architecture but does not consider both business and IT sides of EA implementation.

Schmidt and Buxmann (2010) proposed a CSF model for EA. Without comprehensive EA implementation, it is difficult to adapt the business process and IT. EA has a specific role in evolving ISs through developing new systems and incorporating new technologies to attain the enterprise's mission [22]. Schmidt and Buxmann (2010) highlighted IT efficiency and IT flexibility as two dimensions of the dominant EA management (EAM) goals. The degree of stakeholder participation should be taken into account as well. Therefore, the EAM approach is conceptualized along seven dimensions, including EA documentation, EA planning, EA programming, EA implementation, EA communication and support, EA governance, and stakeholder participation [22]. This model focuses more on EAM rather than EA implementation, but there are additional factors affecting successful EA implementation.

Aier and Schelp (2010) indicated that most enterprises desire to implement EA for IT improvements and business process changes. Although EA implementation is rather acceptable and rational among practitioners, it is still immature. In this regard, recognizing CSFs is of principal significance to EA implementation and future effects. EA is a mechanism for agility, consistency, compliance, and efficiency for both the business and IT processes. Enterprises have recently been encountering barriers during EA implementation, which requires redefining certain processes as a result of the lack of familiarity with CSFs [23]. Aier and Schelp (2010) categorized the identified factors into contextual, structural, and process-related. According to their analysis, communication skills and training of enterprise architects contribute to EA success [23]. Though this model covers EA implementation, it does not cover EA practices.

Tanja Ylimaki (2006) mentioned that the majority of managers in industry and the academic field have considered EA in various areas such as ISs, business processes, innovation monitoring, and business environment changes [24]. EA can be an efficient method to align business processes with IT. Ylimaki (2006) identified several important CSFs for ensuring successful EA implementation [24]:

- Business-driven approaches

- Commitment

- Methodology and tool support development

- EA models and artifacts

- EA governance

- $\quad$ Project and program management

- Assessment and evaluation

- IT investment and acquisition strategies

- $\quad$ Skilled teams, training and education

- Organizational culture

Tanja Ylimaki aimed to provide insight into the CSFs for EA that must be achieved exceedingly well in order to attain high-quality EA, which will consequently enable businesses to become more successful.

Analysing the occurrence of CSFs within the literature presented above reveals that EA implementation is one of the most challengeable projects that necessitates a comprehensive roadmap to cover all EA aspects. Many EA implementation projects should consist of several practices with various characteristics. Thus, familiarity with 
general CSFs can assist enterprises to implement EA appropriately, where CSFs serve as input to project management practice, which can lead directly or indirectly to EA project success. The aforementioned models mostly focus on the IT architecture and management aspects of EA implementation or evaluation based on a qualitative approach. However, the focus of this research is on EA implementation and factor evaluation using a quantitative approach.

\section{RESEARCH MODEL AND HYPOTHESES}

The CSFs for EA implementation were derived from interviews with the experts and prior research works. Semistructured interviews were conducted with EA experts working at the Department of Enterprise Architecture of the Malaysian Administrative Modernisation and Management Planning Unit (MAMPU). The participants had specific expertise in EA, and particularly with implementation methods and frameworks. Moreover, they were employees from the middle and high management levels. Next, previous literature was reviewed extensively, taking into account related EA implementation results. The most common factors were selected from the literature and combined with the interview results. The interview and literature review results were consolidated to constitute the independent variables of the present research model. The literature review also made evident that many success factors are validated in various EAs concurrently.

Appropriate CSFs can lead enterprise resources in the desired direction and help establish a successful competition environment [25][2]. With respect to EA projects, several factors need to be considered. It is obvious that EA projects bear no similarities to each other as each EA project has specific features and characteristics in terms of enterprise activities, time and budget.

\subsection{Identified Factors}

Five factors were selected for the proposed CSF model based on the interviews conducted and the literature review. This section describes the identified factors, which are also known as constructs [1].

\section{- Team Capability}

Team capability refers to a domain of knowledge, whereby the EA team should have experts with proper knowledge of EA concepts. In addition, the team should have the ability to achieve the enterprise's goals. Both business and technical knowledge are substantial in achieving successful implementation [24][15].

\section{- Communication}

Communication refers to achieving the common understanding, agreement and a shared view of the EA scope, vision, and objectives as well as developed models and other artefacts. Communication is an important means of gaining commitment to the EA effort [26]. Effective communication eliminates ambiguities, leading to explicit process requirements, as well as positively influences EA acceptance and adoption. Communication among stakeholders and EA team members can be in the forms of progress reports, weekly or monthly meetings, or other communication tools to update stakeholders on the implementation progress [26][27].

\section{- Top Management Commitment}

Top management commitment refers to enterprise managers and EA executive managers who should sponsor all potential employees, users, applications, and current and future systems involved during implementation [28][2]. Managers are actively involved in creating adequate resources and supporting rapid decisions on project acceptability and necessary requirements. Moreover, they assign the required resources to EA projects. They also participate in the entire project process and should have adequate power to execute the project plan and coordinate all implementation phases [1][7] .

\section{- Technology and Infrastructure}

This factor refers to the assessment of an enterprise's IT readiness, including the architecture, infrastructure, hardware and software. Improvements in IT complexity and IT-business process alignment require efficient technology tools for successful EA implementation [29][30]. During EA implementation, infrastructure may need upgrading or revamping. EA implementation obviously involves a complex transition from current to 
desired architecture and collective business processes throughout the enterprise. Therefore, adequate IT infrastructure, hardware, software and networking are fundamental prerequisites for this purpose $[22][29][21][52]$.

\section{- Governance}

Governance refers to the consistency and timeliness of an EA implementation process. EA projects require effective governance and monitoring approaches to reduce project failure. Governance is essentially about ensuring that a business process is conducted properly [31][32]. It is less about overt control and strict adherence to rules, and more about guidance and effective and equitable resource usage to ensure sustainability of an enterprise's strategic goals [11]. EA metrics (standards, framework) can be used as governance tools to measure the effectiveness and progress of implementation. Governance creates advanced blueprints of all business and IT processes that are required to achieve the target architecture [31][33].

\section{- $\quad$ Success}

This study presents three different attributes to identify overall EA project success: quality (desired architecture delivery), time (on-time EA implementation) and cost (EA implementation within the estimated budget) [34].

\subsection{Research Hypotheses}

The followings null and alternative hypotheses are defined for each independent factor in this research: $\mathrm{H} 0=$ There is no relationship between Team capability, Communication, Top Management Commitment, Technology and Infrastructure, Governance, and EA Implementation Success.

$\mathrm{HA}=$ There is a meaningful relationship between Team capability, Communication, Top Management Commitment, Technology and Infrastructure, Governance, and EA Implementation Success.

\subsection{Research Model}

Figure 1 illustrates the current research model, which represents the relationships between the aforementioned independent factors and the success of EA implementation as the dependent factor.

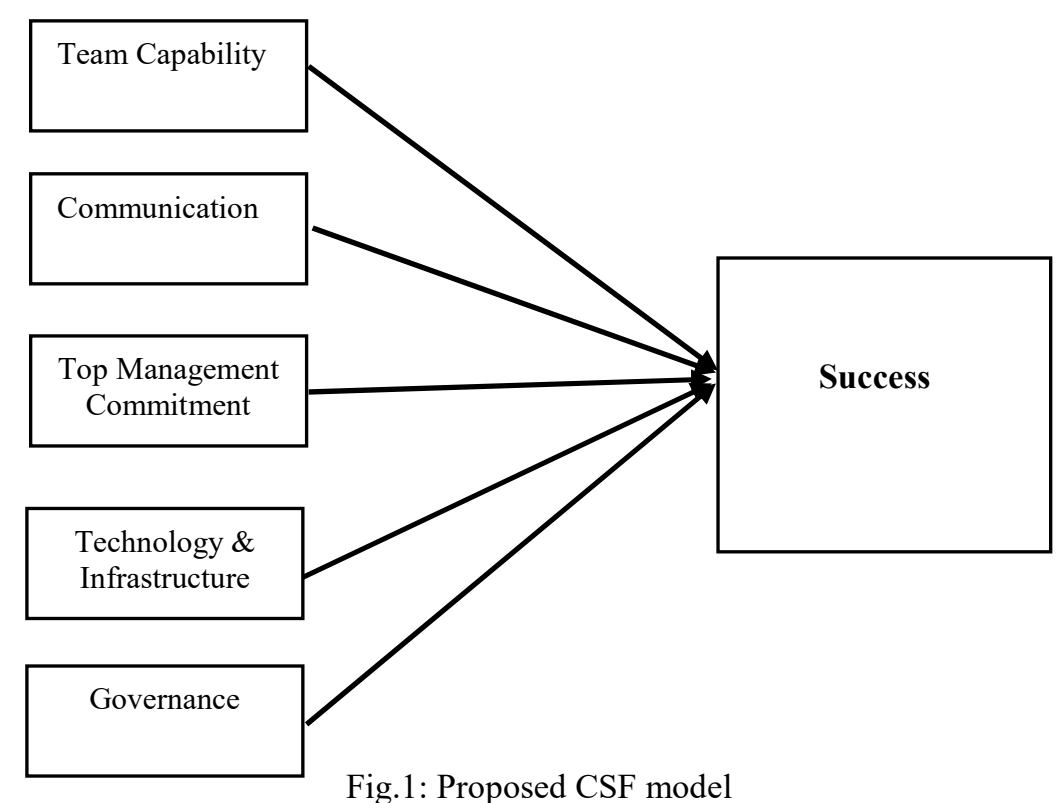

Equation (1) shows the relationship between the success of EA implementation and the independent factors.

$Y=b_{0}+b_{1} X_{1}+b_{2} X_{2}+b_{3} X_{3}+b_{4} X_{4}+b_{5} X_{5}$ 
Where $\mathrm{Y}$ is the success of EA implementation as the dependent variable and $\mathrm{b} 0, \mathrm{~b} 1, \mathrm{~b} 2, \mathrm{~b} 3, \mathrm{~b} 4, \mathrm{~b} 5$ are the Standardized Regression Coefficients (Beta) for the independent variables (top management commitment, technology and infrastructure, governance, EA team capability, and communication).

\subsection{Operationalization of Constructs}

In order to test the aforementioned hypotheses, the measurable items must operationalize the constructs. According to Hair [35], such scales can either be derived from previous research or new construct measures [1]. In the present research, the construct items were obtained from previous research, and were developed based on items from the literature. Similar to construct development, expert opinions were also included. The items did not result in any additional scales to those derived from literature. This procedure prevented potential bias that may arise from our understanding and anticipation of EA implementation success when operationalizing CSFs that affect EA implementation success. Table 1 lists the constructs used in this research along with their respective measurement items. For each item, the corresponding references are added as well.

Table 1: Operationalization of constructs

\begin{tabular}{|c|c|c|c|}
\hline Construct & Item & Description & Reference \\
\hline \multirow{5}{*}{$\begin{array}{l}\text { Top } \\
\text { management } \\
\text { commitment }\end{array}$} & M1 & $\begin{array}{l}\text { The project received top management support with influence on } \\
\text { decision-making (full participation in all EA project steps) }\end{array}$ & {$[34][24]$} \\
\hline & M2 & $\begin{array}{l}\text { The project objectives were well-suited to the needs of the } \\
\text { enterprise }\end{array}$ & {$[24][11]$} \\
\hline & M3 & Change management was utilized within the EA project & {$[24][28][36]$} \\
\hline & M4 & Appropriate team members were selected for the EA project & [24][23] \\
\hline & M5 & The roles of EA stakeholders were clearly defined & [37][38] \\
\hline \multirow{3}{*}{$\begin{array}{l}\text { Technology } \\
\text { and } \\
\text { infrastructure }\end{array}$} & $\mathrm{T} 1$ & $\begin{array}{l}\text { The project included appropriate software modelling and } \\
\text { development }\end{array}$ & [39][40] \\
\hline & $\mathrm{T} 2$ & $\begin{array}{l}\text { Appropriate infrastructure was provided for the enterprise (e.g. } \\
\text { network, hardware, etc.) }\end{array}$ & [39][28] \\
\hline & T3 & Project team members received appropriate technical training & [24][39] \\
\hline \multirow[t]{4}{*}{ Governance } & G1 & $\begin{array}{l}\text { The enterprise defined and documented the architecture } \\
\text { governance structure }\end{array}$ & [24][40] \\
\hline & G2 & $\begin{array}{l}\text { The enterprise defined and documented the roles, } \\
\text { responsibilities and authorization }\end{array}$ & [24][28] \\
\hline & G3 & $\begin{array}{l}\text { The enterprise monitored the transition plan structure and } \\
\text { strategies }\end{array}$ & [23][41] \\
\hline & G4 & $\begin{array}{l}\text { The project employed proper architectural frameworks, } \\
\text { methodologies and processes }\end{array}$ & [23][24] \\
\hline \multirow[t]{5}{*}{$\begin{array}{l}\text { EA team } \\
\text { capability }\end{array}$} & HR1 & $\begin{array}{l}\text { The EA implementation team must have comprehensive } \\
\text { knowledge about EA }\end{array}$ & [24][36] \\
\hline & HR2 & The EA implementation team must have great motivation & [23][28] \\
\hline & HR3 & Team members exhibit good interaction and cooperation & [14][24] \\
\hline & HR4 & EA teams have appropriate skills and competence & [24][22] \\
\hline & HR5 & Suitable training and education for EA teams & [24][22] \\
\hline \multirow[t]{3}{*}{ Communication } & $\mathrm{C} 1$ & $\begin{array}{l}\text { Stakeholders' satisfaction is considered during EA } \\
\text { implementation }\end{array}$ & [37][42] \\
\hline & $\mathrm{C} 2$ & Centralized information for common understanding of decisions & [37][22] \\
\hline & $\mathrm{C} 3$ & $\begin{array}{l}\text { There is good communication between the project team and } \\
\text { stakeholders }\end{array}$ & [37][42] \\
\hline \multirow[t]{3}{*}{ Success of EA } & S1 & $\begin{array}{l}\text { The EA implementation was successful in terms of project } \\
\text { completion timeliness }\end{array}$ & [43][14] \\
\hline & S2 & $\begin{array}{l}\text { The EA implementation was successful in terms of desired } \\
\text { architecture achievement }\end{array}$ & [14][40] \\
\hline & S3 & $\begin{array}{l}\text { The EA implementation was successful in terms of cost and } \\
\text { effort being under budget or within estimates }\end{array}$ & [14][28] \\
\hline
\end{tabular}


In this study, the survey research method was selected in order to achieve the intended research objective. In this regard, a questionnaire served as the research instrument. The processes and procedures introduced by Kasunic (2005)[44] were also utilized and considered.

\subsubsection{Instrument Development}

A structured, self-administered and Web-based questionnaire was created to evaluate the proposed model. The questionnaire designed consists of 27 short, closed-ended questions that are easy to complete. Questions were prepared relating to the CSFs that contribute to EA implementation. The questionnaire comprises two segments: the first consists of general information on the respondents' background, and the second segment investigates each CSF and its relationship with the success of EA implementation. The seven-point Likert scale was used to answer each question.

\subsubsection{Data Collection}

Two academic experts familiar with quantitative research assessed and reviewed the content validity of the research questionnaire. The experts focused on reviewing the format, order, spacing, font, spelling and, the Likert scale used. The experts' feedback served to refine and enhance the questionnaire.

Subsequently, a pilot study was conducted with 10 EA practitioners who answered the questionnaire in order to identify potential question weaknesses and avoid questionnaire complexity. The EA practitioners provided some comments on the demographic questions, ordered some items for each factor, and corrected some parts of the questions to achieve better results. The following criteria were set for the survey population:

- Those with at least 2 years of practical experience in EA implementation

- Those working as IT managers, IT consultants or Enterprise Architects

The data were collected during a TOGAF workshop and seminar in Cyberjaya, Malaysia. Eighty-eight (88) questionnaires were filled out and completed.

\subsubsection{Analysis Technique}

In the present research analysis, descriptive statistics, reliability, factor analysis, correlation, and regression tools were utilized to justify the proposed research model with the dependent factor (EA implementation success) and independent factors. SPSS version 19.0 was used for validation.

In evaluating the identified factors, Factor Analysis was employed to understand the underlying structure of the indicators of each construct [45]. In addition, Pearson Correlation was used to measure the strength of the relationships between the independent factors and dependent factor. Moreover, to attain an appropriate foundation for research model evaluation, Multiple Regression was utilized to explore the predictive ability of the independent factors on the dependent factor [45]. Multiple regressions also facilitated the comparison of the predictive ability of particular factors and identifying the best factors that predict EA implementation success.

\subsection{DATA ANALYSYS AND RESULTS}

This section presents the results of analysing the identified factors with SPSS 19.

\subsection{Descriptive Analysis for the Questionnaire}

This section represents the descriptive analysis based on the general questions in the designed questionnaire that relate to the respondents' characteristics. Descriptive analysis was carried out for the first and second parts of the questionnaire. A frequency table is one way to gain a holistic view of the frequency of each variable, especially the respondents' characteristics. Figure 2 summarizes the demographic profiles of the respondents. 


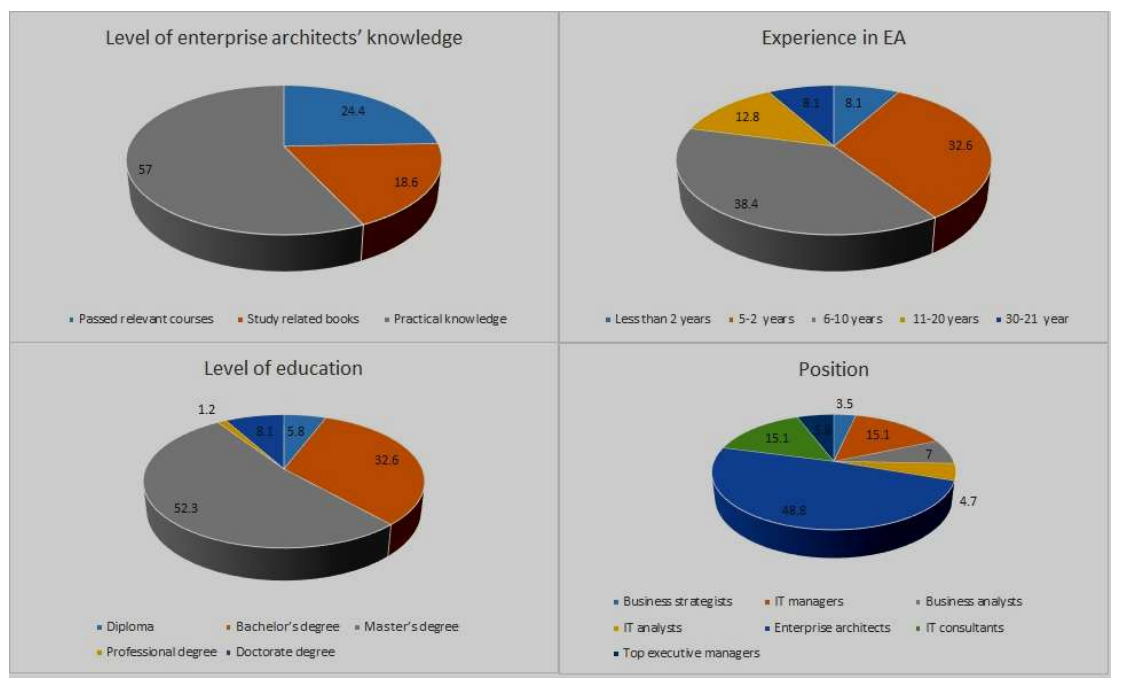

Fig.2: Demographic profiles of respondents (\%)

Figure 2 shows that 49 respondents (57\%) have practical knowledge. In contrast, only 21 respondents $(24.4 \%)$ pass relevant courses; 16 respondents studied related books (18.6\%); the majority, $45(52.3 \%)$, possess a Master's degree, while $28(32.6 \%)$ have a Bachelor degree. Most respondents, $42(48.8 \%)$, are enterprise architects, while $13(15.1 \%)$ are IT managers and IT consultants, $6(7 \%)$ are business analysts, and $5(5.8 \%)$ are top executive managers. Furthermore, 33 respondents have 6-10 years' experience in EA projects $(38.4 \%), 28$ (32.6\%) have 2-5 years' experience, 11 (12.8\%) have 11-20 years' experience, and finally, 7 (8.1\%) have 21-30 and less than 2 years' experience in EA.

\subsection{Data Analysis}

This section illustrates the factor analysis and reliability of the main questionnaire. On top of that, the correlation and regression are represented to demonstrate the correlation of each factor with the dependent factor.

\subsubsection{Factor Analysis}

Factor analysis is a statistical method used to classify observations into smaller groups. It is one of the most common research methods for detecting hidden characteristics, making statistical observations, and categorizing variables [46]. Sample adequacy of the collected data for factor analysis must be ensured [2,3]. For this purpose, the KMO and Bartlett's tests were applied. Table 2 indicates the KMO measure is 0.744 , meaning that the current data set is suitable for factor analysis. For Bartlett's test, sig. is 0 , meaning that all variables are sufficiently correlated to provide a reasonable basis for factor analysis. Principal axis factor analysis was Conducted on all CSF questions.

Table 2: KMO and Bartlett's measures

\begin{tabular}{lcr}
\hline Kaiser-Meyer-Olkin Measure of Sampling Adequacy & \multicolumn{1}{c}{$\mathbf{7 4 4}$} \\
\hline Bartlett's Test of Sphericity & Approx. Chi-Square & 1477.584 \\
& df & 253 \\
& Sig & .000 \\
\hline
\end{tabular}


The factor loading of each variable was achieved based on factor analysis and the rotated factor matrix concept [46].

Table 3: Factor loading matrix results

\begin{tabular}{|c|c|c|c|c|c|c|}
\hline & \multicolumn{6}{|c|}{ Factor } \\
\hline & 1 & 2 & 3 & 4 & 5 & 6 \\
\hline M1 & .653 & -.230 & .164 & .133 & .156 & .373 \\
\hline M2 & .826 & -.044 & .270 & .234 & -.068 & .165 \\
\hline M3 & .733 & .156 & .066 & .221 & -.019 & -.067 \\
\hline M4 & .716 & .220 & .148 & .065 & -.064 & .107 \\
\hline M5 & .722 & .023 & .182 & .110 & .293 & .236 \\
\hline $\mathrm{T} 1$ & .167 & -.049 & -.019 & .719 & .059 & .300 \\
\hline $\mathrm{T} 2$ & .169 & .144 & .000 & .813 & .194 & .121 \\
\hline $\mathrm{T} 3$ & .276 & .261 & .005 & .775 & .209 & .077 \\
\hline $\mathrm{O} 1$ & .126 & .265 & .285 & .153 & .138 & .369 \\
\hline $\mathrm{O} 2$ & .144 & .233 & .236 & .345 & -.025 & .298 \\
\hline O3 & .086 & .152 & .238 & .176 & .113 & .838 \\
\hline $\mathrm{O} 4$ & .214 & .217 & -.102 & .189 & .010 & .682 \\
\hline HR1 & .088 & .716 & -.102 & -.225 & -.056 & .348 \\
\hline HR2 & .084 & .666 & .225 & .191 & -.260 & .002 \\
\hline HR3 & -.042 & .658 & .421 & .287 & -.105 & -.070 \\
\hline HR4 & .110 & .813 & .226 & .000 & -.023 & .201 \\
\hline HR5 & .008 & .668 & .115 & .250 & -.009 & .063 \\
\hline $\mathrm{C} 1$ & .196 & .107 & .815 & .029 & .099 & .072 \\
\hline $\mathrm{C} 2$ & .217 & .244 & .858 & .008 & -.160 & .096 \\
\hline $\mathrm{C} 3$ & .215 & .206 & .910 & -.042 & -.129 & .117 \\
\hline SUCCESS1 & -.001 & -.113 & -.084 & .144 & .815 & .049 \\
\hline SUCCESS2 & .039 & -.075 & -.070 & .102 & .960 & .059 \\
\hline SUCCESS3 & .180 & -.098 & .066 & .194 & .465 & .422 \\
\hline
\end{tabular}

NOTE: MM: Management Commitment, MT: Technology \& Infrastructure, MG: Governance, MHR: Team Capability, MC: Communication, MS: Success

Table 3 shows the factor loadings for all 22 items. A frequently used rule specifies that only variables with loading above 0.5 should be considered [47]. Every item should be located in a separate column regardless of the sign.

The first five items' high loadings are located in the first column, which is "Top Management Commitment." "Technology and infrastructure" is in column 3, the variables for "EA team capability" are in column 2, the variables for "Governance" are in column 5, the variables for "Communication" are in column 6, and the variables for measuring "Successful Implementation" are in column 4. The loadings for "O1" and "O2" in column 3 are not desirable nor have high loading on other factors and can thus be omitted from other analyses. The same is true for the "success 3" variable where the factor loading is not high in column 4 and other columns, so it is also omitted from the main analysis.

\subsubsection{Reliability}

Reliability is an instrument to identify the stability of the research and test results [48]. In this research, Cronbach's Alpha was used to test reliability. Table 4 presents the reliability test results. 
Table 4: Reliability test

As shown in are at an acce

\begin{tabular}{l|c}
\hline \multicolumn{1}{c|}{ Factor } & Cronbach's Alpha \\
\hline Top management commitment & .881 \\
Technology and Infrastructure & .895 \\
Governance & .735 \\
EA team capability & .846 \\
Communication & .866 \\
Success & .817 \\
\hline
\end{tabular}

\subsubsection{Correlation}

The correlation technique was employed to investigate the relationships between the identified factors (independent variables) and success of EA implementation (dependent variable). This served to determine the strength of the relationships as interpreted based on Cohen's measurement [45].

Table 5: Relations between CSFs and success of EA implementation

\begin{tabular}{|c|c|c|c|c|c|c|c|}
\hline & & MS & MM & MT & MG & MHR & MC \\
\hline \multirow[t]{3}{*}{$\overline{M S}$} & Pearson Correlation & 1 & $.575^{* *}$ & $.577^{* *}$ & $.569^{* * *}$ & $.539^{* * *}$ & $.514^{* *}$ \\
\hline & Sig. (2-tailed) & & .000 & .000 & .000 & .000 & .000 \\
\hline & $\mathrm{N}$ & 86 & 86 & 86 & 86 & 86 & 86 \\
\hline \multirow[t]{3}{*}{$\mathrm{MM}$} & Pearson Correlation & $.575^{* *}$ & 1 & $.394^{* *}$ & $.345^{* *}$ & $.311^{* *}$ & $.374^{* *}$ \\
\hline & Sig. (2-tailed) & .000 & & .000 & .001 & .004 & .000 \\
\hline & $\mathrm{N}$ & 86 & 86 & 86 & 86 & 86 & 86 \\
\hline \multirow[t]{3}{*}{ MT } & Pearson Correlation & $.577^{* *}$ & $.394^{* *}$ & & $.332^{* *}$ & $.456^{* *}$ & $.432^{* *}$ \\
\hline & Sig. (2-tailed) & .000 & .000 & 1 & .002 & .000 & .000 \\
\hline & $\mathrm{N}$ & 86 & 86 & 86 & 86 & 86 & 86 \\
\hline \multirow[t]{3}{*}{ MG } & Pearson Correlation & $.569^{* *}$ & $.345^{* *}$ & $.332^{* *}$ & 1 & $.345^{* *}$ & $.229^{*}$ \\
\hline & Sig. (2-tailed) & .000 & .001 & .002 & & .001 & .018 \\
\hline & $\mathrm{N}$ & 86 & 86 & 86 & 86 & 86 & 86 \\
\hline \multirow[t]{3}{*}{ MHR } & Pearson Correlation & $.539^{* *}$ & $.311^{* *}$ & $.456^{* *}$ & $.345^{* *}$ & 1 & $.365^{* *}$ \\
\hline & Sig. (2-tailed) & .000 & .004 & .000 & .001 & & .001 \\
\hline & $\mathrm{N}$ & 86 & 86 & 86 & 86 & 86 & 86 \\
\hline \multirow[t]{3}{*}{$\mathrm{MC}$} & Pearson Correlation & $.514^{* *}$ & $.374^{* *}$ & $.432^{* *}$ & $.229^{*}$ & $.365^{* *}$ & 1 \\
\hline & Sig. (2-tailed) & .000 & .000 & .000 & .018 & .001 & \\
\hline & $\mathrm{N}$ & 86 & 86 & 86 & 86 & 86 & 86 \\
\hline
\end{tabular}
(2-tailed).

NOTE: MM: Management Commitment, MT: Technology \& Infrastructure, MG: Governance, MHR: Team Capability, MC: Communication, MS: Success

In Table 5, there is a strong correlation between the Success of EA Implementation as the dependent variable and Top Management Commitment, Technology and Infrastructure, Governance, EA Team Capability, and Communication as independent variables. Based on the Pearson correlation statistical test, for management commitment $\mathrm{r}=0.575$ and $\mathrm{p}$-value $=0(<0.05)$. These measurements indicate there is a positive and strong relationship between Top Management Commitment, and the Success of EA Implementation.

Table 6 also presents the Pearson correlation for MT (Technology and Infrastructure) with $r=0.577$ and $p$-value $=0(<0.05)$, (H0 rejected), indicating there is a significant, positive relationship between Technology and Infrastructure and the Success of EA Implementation. The Pearson correlation for MG (Governance) with $\mathrm{r}=$ 0.569 and $\mathrm{p}$-value $=0(<0.05)(\mathrm{H} 0$ rejected $)$. These measurements indicate there is a positive, strong and 
significant relationship between Governance and Success of EA Implementation. The Pearson correlation for MHR (EA team capability) is 0.539 and the p-value is $0(<0.05)$, ( $\mathrm{H} 0$ rejected), signifying there is a positive relationship between EA Team Capability and the success of EA implementation at a significant level. Moreover, the Pearson correlation for MC (Communication) is 0.514 and the p-value is $0(<0.05)$, (H0 rejected). These measurements indicate a positive and strong relationship between Communication and Success of EA Implementation at a significant level.

Finally, based on the Pearson correlation analysis, the proposed CSF model contains significant relationships between the independent variables and dependent variable. Thus, all H0 hypotheses are rejected in favour of H1.

\subsubsection{Regression Analysis}

Regression analysis enables researchers to predict changes in the dependent and independent variables and to identify the contributions of each independent variable to explaining the dependent variable [45].

Table 6: Variables entered/removed

\begin{tabular}{|c|l|l|l|}
\hline Model & Variables Entered & Variables Removed & Method \\
\hline 1 & MC, MG, MHR, MM, MT & 0 & Enter \\
\hline \\
a. All requested variables entered. \\
b. Dependent Variable: MS
\end{tabular}

Table 6 indicates that five independent variables were entered and no variables were removed from this model. After entering all independent variables into the model, the following output was achieved.

Table 7: Model summary

\begin{tabular}{ccccc}
\hline Model & R & R Square & Adjusted R Square & Std. Error of the Estimate \\
\hline 1 & $.793^{\text {a }}$ & $\mathbf{. 6 2 8}$ & $\mathbf{. 6 0 5}$ & .68405 \\
\hline
\end{tabular}

Table 7 represents the final model in which all independent variables were entered. R-square indicates the fraction of variation in the dependent variable as predicted by the independent variables. In this research $\mathrm{R}$ square is 0.628 , which means this model explains $63 \%$ of EA implementation success.

Collinearity statistics is another measure that focuses on tolerance and VIF, and shows multicollinearity. If this measure is $<1-\mathrm{R}^{2}$, there is a problem with multicollinearity (Barrett and Morgan Jr, 2005). As Table 8 indicates, $\mathrm{R}^{2}$ is $0.628,1-\mathrm{R}^{2}$ is about 0.372 and all tolerance is greater than 0.375 , so multicollinearity is not a problem. 
Table 8: Multiple regression analysis results

\begin{tabular}{|c|c|c|c|c|c|}
\hline \multirow[t]{2}{*}{ Variables } & \multirow[t]{2}{*}{ Beta } & \multirow[t]{2}{*}{$\mathbf{t}$} & \multirow[t]{2}{*}{ Sig. } & \multicolumn{2}{|c|}{ Collinearity Statistics } \\
\hline & & & & Tolerance & VIF \\
\hline Top Management Commitment & 0.241 & 3.194 & 0.002 & 0.749 & 1.336 \\
\hline Technology and Infrastructure & 0.221 & 2.639 & 0.010 & 0.665 & 1.503 \\
\hline Governance & 0.292 & 3.920 & 0.000 & 0.801 & 1.249 \\
\hline EA team capability & 0.201 & 2.423 & 0.018 & 0.720 & 1.390 \\
\hline Communication & 0.172 & 2.117 & 0.037 & 0.739 & 1.354 \\
\hline Note: $R=0.793, R$ Square $=0.62$ & Adjus & Squ & $.605, F=$ & value $=0$ & \\
\hline
\end{tabular}

\subsection{Model of EA Implementation Success}

Table 8 demonstrates that all CSFs are significant factors contributing to the EA implementation success model. In short, a combination of management, technology and infrastructure, governance, EA team capability, and communication can significantly predict the success of EA implementation because the P-value (sig.) is less 0.05 . The success of EA implementation was predicted by top management commitment $(\beta=0.241)$, technology and infrastructure $(\beta=0.221)$, governance $(\beta=0.292)$, EA team capability $(\beta=0.201)$ and communication $(\beta=0.172)$. These variables together explain $63 \%$ of variance in EA implementation (R-square $=0.628)$. Finally, governance seems to be the strongest contributor to the success of EA implementation. Figure 3 shows the exact prediction of each factor.

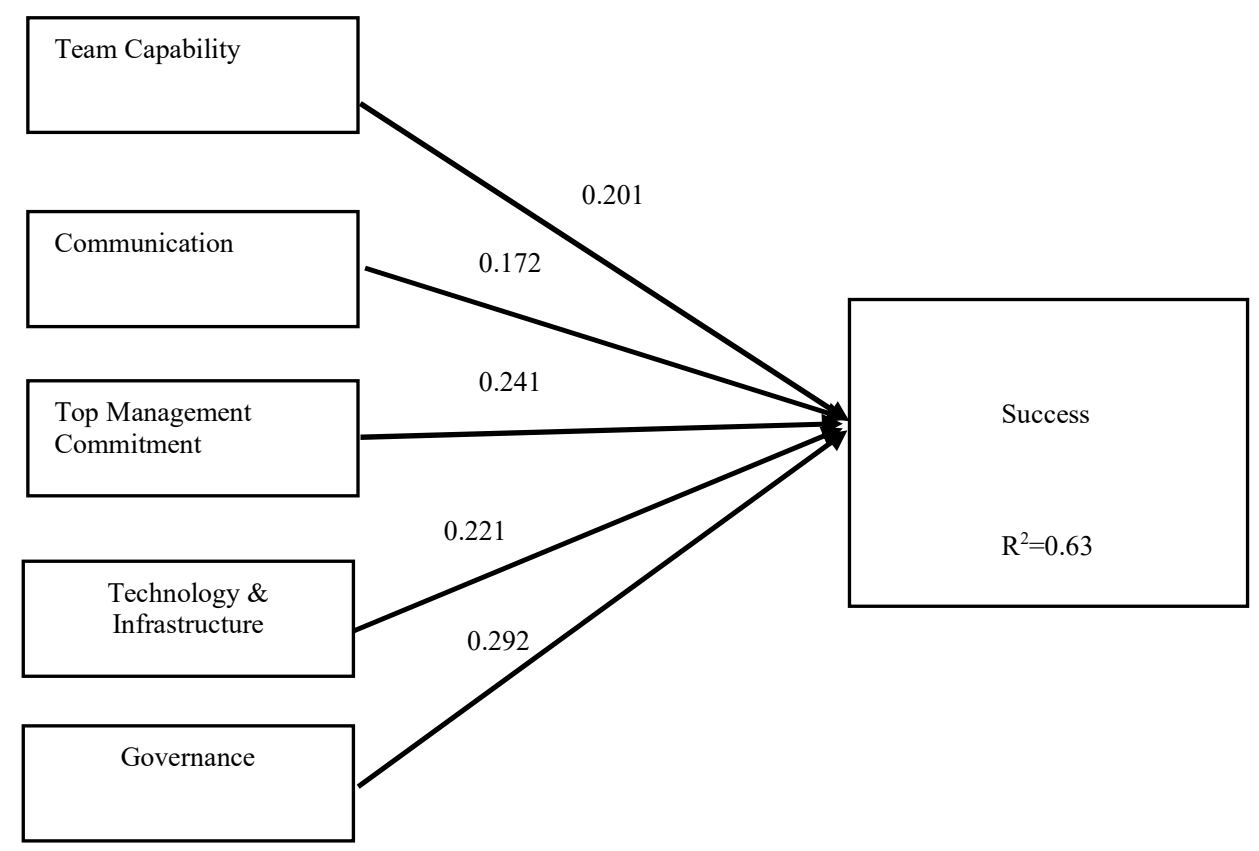

Fig.3: Prediction of each factor in the CSF model 


\subsection{DISCUSSION}

Identifying CSFs is fundamental in successful EA implementation. The present study identified a comprehensive CSF model for implementing EA. Although there are studies in the literature that refer to factors of EA implementation, many current CSF models only focus on the IT dimension of EA implementation. The main feature of this research was considering the factors that affect all aspects of EA implementation. In this regard, management commitment, technology and infrastructure, team capability, governance, and communication were the factors evaluated in this study, which are related to the business and technology aspects of EA implementation.

Governance is the factor with the highest influence on EA implementation success. Governance refers to the consistency and timeliness of the EA implementation process, which requires effective governance and monitoring approaches to reduce the risk of project failure. It is essentially about ensuring that business is conducted properly.

Although previous literature provides important insight into various factors that should be of major concern for EA implementation, those factors are not ignored in the currently proposed model. One of the most important insights from this article regards using the quantitative method to evaluate the proposed CSF model.

Today, there are insufficient effective structured models that cover all aspects of EA implementation. Moreover, current CSF models are evaluated based on qualitative methodology.

\subsection{Research Contributions}

The results of this research have some implications for future research and practices. A CSF model was proposed for EA implementation, which can be useful for enterprise architects and practitioners. By understanding the CSF model from the start of a project, practitioners can plan and focus on the CSFs to achieve the desired results.

From a stakeholder perspective, this CSF model may influence desired EA project achievement time upon understanding the project's success factors. Consequently, stakeholders will be satisfied and the desired architecture will be obtained.

The findings of this study may have an impact on related work. A CSF model was proposed based on an empirical investigation and by considering existing models. Besides, factors were identified and evaluated by means of the survey research method.

\subsection{Study Limitations and Recommendations}

This study has some limitations, one of which is that the survey sampling was narrow; however, the respondents were experts. The second limitation regards the implementation of the identified factors, whereby in real projects, these factors may provide more information than statistical analysis.

In order to obtain better results in future research, it is essential to consider the following recommendations:

- Research should include larger sample sizes

- Similar studies should be performed in other industries, such as the telecommunication or education sectors; the research scope can be extended to increase result reliability; and the findings and results should be compared and evaluated.

- Additional factors that potentially affect the success of EA implementation should be investigated to reduce failure. The factors can be understood more in-depth by using a mix-mode methodology (quantitative and qualitative data collection).

\section{CONCLUSIONS}

In this research, the proposed CSF model for EA implementation was analysed. Related factors that affect EA implementation success were identified in the literature and from semi-structured interviews conducted with EA experts working at the Department of Enterprise Architecture of the Malaysian Administrative Modernisation and Management Planning Unit (MAMPU). 
The correlation analysis indicated that the independent variables, including Top Management Commitment (M), Governance (G), Technology \& Infrastructure (T), EA Team Capability (HR), and Communication (C) have significant positive relationships with the Success of EA Implementation as the dependent variable.

The multiple regression analysis shows that five variables proved to have critical relationships with the success of EA implementation. The variables are Management Commitment (M), Governance (G), Technology \& Infrastructure (T), EA Team Capability (HR), and Communication (C). The results suggest that $63 \%$ (Adjusted $\mathrm{R}^{2}=628 \%$, F-value $=27.037$, p-value $\left.<.05\right)$ of successful EA implementation can be explained by these five critical variables.

Multiple regression analysis was also applied to examine the effects of each factor on the success of EA implementation. The study results indicate that Governance is the strongest predictor of successful EA implementation $(\beta=0.292, \mathrm{p}<.05)$.

The descriptive information in Table 1 indicates that most respondents have 6-10 years' experience in EA (33 respondents, or $38.4 \%)$. The most important point in the table is that nearly all participants (57\%) have practical knowledge in EA.

Based on the results of this study and the CSF model, Governance has the strongest effect on EA implementation success. This model can explain $63 \%$ of successful EA implementation, which is supported by another recent study on EA implementation. It was also revealed that the success of EA implementation is strongly related to Management Commitment, Governance, Technology \& Infrastructure, EA Team Capability, and Communication.

This research was intended to enhance understanding of both generic and unique critical factors that affect EA implementation success. A CSF model was proposed to guide research in EA implementation success and the survey results were analysed with the aim to explore the CSFs and EA implementation success. Subsequently, this research offered insight into the relationships between the CSFs and EA implementation success. The quantitative research methodology was used in this study. The current research results can contribute to both the academic field and business industry. In short, a specific set of five CSFs were highlighted: top management commitment, governance, IT and infrastructure, EA team capability, and communication, which have an impact on successful EA implementation. It was demonstrated there is a statistically significant and positive relationship between each of the five CSFs and the success of EA implementation. Moreover, governance is of the highest importance in EA implementation.

\section{REFERENCES}

[1] S. Aier, "The role of organizational culture for grounding, management, guidance and effectiveness of enterprise architecture principles," Information Systems and e-Business Management, vol.12, no.1, 2014, pp.43-70.

[2] J. Löhe and C. Legner, "Overcoming implementation challenges in enterprise architecture management: a design theory for architecture-driven IT Management (ADRIMA)," Information Systems and eBusiness Management, vol. 12, no. 1, Feb. 2013, pp. 101-137.

[3] Bradley, R. V., Pratt, R. M., Byrd, T. A., Outlay, C. N., \& Wynn Jr, D. E. (2012). "Enterprise architecture, IT effectiveness and the mediating role of IT alignment in US hospitals "Information Systems Journal," vol.22,no.(2), 2012, pp.97-127.

[4] S. Aier, "Understanding the Role of Organizational Culture for Design and Success of Enterprise Architecture Management," Wirtschaftsinformatik, 2013.

[5] K. Frampton and S. Ho, "Case study: Skills analysis for enterprise architects: Implications for university education and curriculum design, Implications for University Education and Curriculum Design." The Journal of Enterprise Architecture," 2010.

[6] Foorthuis, Ralph, Marlies Van Steenbergen, Sjaak Brinkkemper, and Wiel AG Bruls. "A theory building study of enterprise architecture practices and benefits." Information Systems Frontiers (2015): pp.1-24. 
[7] F. Nikpay, H. Selamat, B. D. Rouhani, and P. Nikfard, "A Review of Critical Success Factors of Enterprise Architecture Implementation," in Informatics and Creative Multimedia (ICICM), 2013 International Conference on, 2013, pp. 38-42.

[8] J. Carrillo, A. Cabrera, and C. Román, "Roadmap for the implementation of an enterprise architecture framework oriented to institutions of higher education in Ecuador," Software Technology and Engineering (ICSTE), 2010 2nd International Conference on, vol. 2, pp. V2-7.

[9] A. Šaša and M. Krisper, "Enterprise architecture patterns for business process support analysis," Journal of Systems and Software, vol.84, no.9, 2011, pp.1480-1506.

[10] P. Närman, M. Buschle, and M. Ekstedt, "An enterprise architecture framework for multi-attribute information systems analysis," Software \& Systems Modeling, vol.13, no.3, 2014, pp.1085-1116.

[11] Närman, Per, Ulrik Franke, Johan König, Markus Buschle, and Mathias Ekstedt. "Enterprise architecture availability analysis using fault trees and stakeholder interviews." Enterprise Information Systems, vol.8, no.1 (2014): pp.1-25.

[12] Simon, Daniel, Kai Fischbach, and Detlef Schoder. "An exploration of enterprise architecture research." Communications of the Association for Information Systems, vol.32, no.1 (2013): pp. 1-72.

[13] Gama, Nelson, Pedro Sousa, and Miguel Mira da Silva. "Integrating enterprise architecture and IT service management." In Building Sustainable Information Systems, 2013, pp. 153-165.

[14] D. Stankovic, V. Nikolic, M. Djordjevic, and D. Cao, "A survey study of critical success factors in agile software projects in former Yugoslavia IT companies," Journal of Systems and Software, vol.86, no.6 2013, pp.1663-1678.

[15] E. Niemi and S. Pekkola, "Enterprise Architecture Quality Attributes: A Case Study," in 2013 46th Hawaii International Conference on System Sciences, 2013, pp. 3878-3887.

[16] A. Ojo, T. Janowski, and E. Estevez, "Improving Government Enterprise Architecture Practice--Maturity Factor Analysis," in System Science (HICSS), 2012 45th Hawaii International Conference, 2012, pp. $4260-4269$.

[17] B. Dinter, "Success factors for information logistics strategy—An empirical investigation," Decision Support Systems, vol.54, no.3, 2013, pp.1207-1218.

[18] M. Osterlind and P. Johnson, "Enterprise architecture evaluation using utility theory," in Enterprise Distributed Object Computing Conference Workshops (EDOCW), 2013, 17th IEEE International (pp. 347-351).

[19] Razavi, Mahsa, Fereidoon Shams Aliee, and Kambiz Badie. "An AHP-based approach toward enterprise architecture analysis based on enterprise architecture quality attributes." Knowledge and information systems, vol.28, no.2, (2011): pp.449-472.

[20] C. Pollard and A. Cater-Steel, "Justifications, Strategies, and Critical Success Factors in Successful ITIL Implementations in U.S. and Australian Companies: An Exploratory Study," Inf. Syst. Manag., vol.26, no.2, 2009, pp. 164-175.

[21] T. Kamogawa and H. Okada, "Enterprise Architecture and Information Systems: In Japanese Banking Industry," in Applications and the Internet, SAINT, 2008, pp. 433-436.

[22] C. Schmidt and P. Buxmann, "Outcomes and success factors of enterprise IT architecture management: empirical insight from the international financial services industry," European Journal of Information Systems, vol.20, no.2, 2011, pp. 168-185. 
[23] S. Aier and J. Schelp, "A reassessment of enterprise architecture implementation," in Service-Oriented Computing. Springer Berlin Heidelberg, 2010, pp. 35-47.

[24] T. Ylimäki, "Potential Critical Success Factors for Enterprise Architecture.” University of Jyväskylä, Information Technology Research Institute, 2008.

[25] D. Kundisch, D. J. Veit, T. Weitzel, and C. Weinhardt, Eds., Enterprise Applications and Services in the Finance Industry, vol. 23. Berlin, Heidelberg: Springer Berlin Heidelberg, 2009.

[26] M. Lankhorst, "Enterprise Architecture at Work: Modelling, Communication and Analysis (The Enterprise Engineering Series)," 2013.

[27] B. Van Der Raadt, S. Schouten, and H. Van Vliet, "Stakeholder perception of enterprise architecture," in Software Architecture, Springer Berlin Heidelberg, 2008, pp. 19-34.

[28] M. Alaeddini and S. Salekfard, "Investigating the role of an enterprise architecture project in the business-IT alignment in Iran," Inf. Syst. Front., vol.15, no.1, 2011, pp. 67-88.

[29] S. A. Chun, "Can enterprise architectures reduce failure in development projects?" Transforming Government: People, Process and Policy, vol.6, no.1, 2012, pp. 27-40.

[30] B. van der Raadt, R. Slot, and H. van Vliet, "Experience report: assessing a global financial services company on its enterprise architecture effectiveness using NAOMI," in System Sciences, 2007. HICSS 2007. 40th Annual Hawaii International Conference, 2007, p. 218b-218b.

[31] R. Winter and J. Schelp, "Enterprise architecture governance: the need for a business-to-IT approach," in Proceedings of the 2008 ACM symposium on Applied computing, 2008, pp. 548-552.

[32] Cameron, Brian H., and Eric McMillan. "Analyzing the current trends in enterprise architecture frameworks." Journal of Enterprise Architecture, vol.9, 2013, pp.60-71.

[33] T. Tamm and P. Seddon, "How does enterprise architecture add value to organisations," Communications of the Association for Information Systems, vol.28, no.1, 2011, pp. 141-168.

[34] Iacob, Maria-Eugenia, Lucas O. Meertens, Henk Jonkers, Dick AC Quartel, Lambert JM Nieuwenhuis, and M. J. Van Sinderen. "From enterprise architecture to business models and back," Software \& Systems Modeling, vol.13, no.3, 2014, pp.1059-1083.

[35] J. F. Hair, R. E. Anderson, and R. L. Tatham, "Hair, JF, W. C. (1998), "Multivariate Data Analysis with Readings," vol. 5.

[36] Schmidt, Rainer, Matthias Wissotzki, Dirk Jugel, Michael Mohring, Kurt Sandkuhl, and Alfred Zimmermann. "Towards a framework for enterprise architecture analytics." In 2014 IEEE 18th International Enterprise Distributed Object Computing Conference Workshops and Demonstrations (EDOCW), pp. 266-275.

[37] B. Van der Raadt and M. Bonnet, "The relation between EA effectiveness and stakeholder satisfaction," Journal of Systems and Software, vol.83, no.10, 2010, pp. 1954-1969.

[38] Pruijt, Leo, Raymond Slot, Henk Plessius, and Sjaak Brinkkemper. "The EARScorecard-An Instrument to Assess the Effectiveness of the EA Realization Process," Journal of Enterprise Architecture, 2013, pp.20-31.

[39] T. Iyamu, "The Factors Affecting Institutionalisation of Enterprise Architecture in the Organisation," in Commerce and Enterprise Computing, 2009. CEC'09. IEEE Conference, pp. 221-225.

[40] B. Jahani, S. R. S. Javadein, and H. A. Jafari, "Measurement of enterprise architecture readiness within organizations," Bus. Strateg. Ser., vol.11, no.3, 2010, pp. 177-191. 
[41] E. Niemi and T. Ylimäki, "Enterprise Architecture Evaluation Components," Evaluation of enterprise and software architectures: critical issues, metrics and practices/Eetu Niemi, Tanja Ylimäki \& Niina Hämäläinen (eds.). Jyväskylä: University of Jyväskylä, Information Technology Research Institute, 2008.-(Tietotekniikan tutkimusinstituutin julkaisuja, ISSN 1236-1615; 18). ISBN 978-951-39-3108-7 t. 2008.

[42] J. Yang, G. Q. Shen, M. Ho, D. S. Drew, and A. P. C. Chan, "Exploring critical success factors for stakeholder management in construction projects," J. Civ. Eng. Manag., vol.15, no.4, 2009, pp. 337-348.

[43] H. Isomäki and K. Liimatainen, "Challenges of government enterprise architecture work-stakeholders' views," in Electronic Government, Springer Berlin Heidelberg, 2008 pp. 364-374.

[44] M. Kasunic, "Designing an Effective Survey," Carnegie-Mellon Univ. Pittsburgh, PA Software Engineering Inst, Sept. 2005.

[45] Pallant and Julie, Spss Survival Manual. McGraw-Hill Education (UK), 2013.

[46] B. Thompson, Exploratory and confirmatory factor analysis: Understanding concepts and applications American Psychological Association, 2004.

[47] J. F. Hair Jr., R. E. Anderson, and R. L. Tatham, "Multivariate data analysis with readings (2nd ed.)," Aug. 1986.

[48] E. G. Carmines and R. A. Zeller, Reliability and Validity Assessment, vol. 1. SAGE Publications, 1979.

[49] L. J. Cronbach, "Coefficient alpha and the internal structure of tests," Psychometrika, vol.16, no.3, pp. 297-334, Sept. 1951.

[50] Nikpay, F., Ahmad, R., Rouhani, B. D., \& Shamshirband, S. (2016). A systematic review on postimplementation evaluation models of enterprise architecture artefacts. Information Systems Frontiers, 120.

[51] Nikpay, F., Ahmad, R. B., Rouhani, B. D., Mahrin, M. N. R., \& Shamshirband, S. An effective Enterprise Architecture Implementation Methodology. Information Systems and e-Business Management, 1-36.

[52] Rouhani, B. D., Mahrin, M. N. R., Nikpay, F., Ahmad, R. B., \& Nikfard, P. (2015). A systematic literature review on Enterprise Architecture Implementation Methodologies. Information and Software Technology, 62, 1-20. 